\title{
The Rise of EPR in The UK: A Cross-Sectional Study Examining The Effect of The Transition to EPR on Adherence to VTE Prophylaxis Guidelines in General Surgical Patients
}

Ahmad Almohtadi ( $\square$ ahmad.almohtadi97@gmail.com )

University of London Saint George's https://orcid.org/0000-0002-5974-3330

\section{Malvika Subramaniam}

University of London Saint George's

\section{Anja Mattson \\ University of London Saint George's \\ Bihu Malhotra \\ University of London Saint George's \\ Frida Margaretha Eriksson \\ University of London Saint George's}

\section{Research}

Keywords: Electronic Patient Records, VTE prophylaxis, Low Molecular Weight Heparin, TED stockings, General surgery, National Health Service, NICE guidelines.

Posted Date: September 10th, 2020

DOI: https://doi.org/10.21203/rs.3.rs-71520/v1

License: (1) (1) This work is licensed under a Creative Commons Attribution 4.0 International License. Read Full License 


\section{Abstract}

Background: Hospital-acquired venous thromboembolisms (VTEs) account for $50-60 \%$ of all VTEs observed. Surgical patients are particularly at risk, and preventative measures such as thromboembolism deterrent stockings (TEDs) and low molecular weight heparin (LMWH) proves to be beneficial. The National Quality Requirement in the NHS Standard Contract 2017/19 mandates that $95 \%$ of patients undergo VTE risk assessments. Due to nationwide transitions into electronic patient records (EPR), it is important to observe the impact on the completion of vital assessments such as VTE risk. The aim of this study is to observe the effect of implementing EPR in a tertiary hospital on VTE assessments and prophylaxis administration in admitted surgical patients.

Methods: Using consecutive sampling method, all acute surgical admissions at the St. George's Surgical Admissions Unit from 26th February to 18th March ( $n=154)$ pre-EPR and 31st October to 25th November $(n=151)$ post-EPR implementation were observed for VTE risk assessment, 24-hour re-assessment, prophylaxis (LMWH, TED stockings) prescription, administration, and patient compliance. These two sets of data were compared using a two-tailed $Z$ test to evaluate the effect of EPR on assessment completion, and to observe if national targets were met.

Results: Pre-EPR, $96 \%$ of patients had a completed VTE assessment, which increased after EPR implementation to $97 \%$ ( $p=0.39$ ). LWMH prescription rates decreased from $82 \%$ to $77 \%$, following EPR $(p=0.14)$. Moreover, TEDs prescriptions decreased from $84 \%$ to $64 \%$ post-EPR $(p<0.01)$. Administration rates of prophylaxis led to a general improvement post-EPR. The 24-hour re-assessment decreased from $62 \%$ to $54 \%$ of patients $(p=0.08)$.

Conclusions: This study demonstrated that current practice met national requirements of VTE assessment. EPR implementation is associated with improved rates in administration of thromboprophylaxis. However, there is still much room for improvement in adherence to risk assessment completion. Data collection post-EPR began immediately after EPR implementation. Thus, lack of confidence and familiarity of the new system could have influenced assessment rates. A multifactorial approach is required when making large transitions, including enhancing staff attitude, increasing EPR training and assessments in individual Trust's technological needs to achieve a standard use capability.

\section{Background}

A venous thromboembolism (VTE) is an acute vascular event, which is a major preventable cause of patient morbidity and mortality in hospitals. VTEs present either as deep venous thrombosis (DVT), venous thromboses typically occurring in the deep veins of the lower leg, or as a pulmonary embolism (PE), a complication of DVT wherein the emboli lodges in the lungs. Once a PE is diagnosed and no further treatment is given, the mortality rate can reach $25 \%$ [1]. 50-60\% of all VTEs seen are hospitalacquired, which are defined as VTEs presenting within 90 days of a hospital admission. The interplay of a variety of factors including venous stasis, vessel injury, and a state of hypercoagulability lead to the formation of a VTE. Hospital patients, in particular trauma and surgical patients, are at significant risk of vascular events, wherein the main contributing factor is often their decreased mobility. This led to extensive public health measures to limit the incidence of hospital acquired VTEs [2].

As such, the National Institute for Health and Care Excellence (NICE) guidance "Venous thromboembolism in over 16s: reducing the risk of hospital acquired deep vein thrombosis or pulmonary embolism" states that all patients admitted to hospital must be assessed for their VTE risk. The guidance sets out to standardise the practice of risk assessment, as well as the management and prevention of DVTs and PEs. Although no particular tool has been mandated, all hospitals must use a tool that is published by a "national United Kingdom (UK) body, professional network or peer-reviewed journal" [3]. The Department of Health's VTE risk assessment is the most commonly used tool; it includes an assessment of mobility, thrombosis, and bleeding risk to advise on appropriate thromboprophylaxis measures (Fig. 1). Furthermore, the guidance states that the assessments should be completed soon after hospital admission, but importantly before the first consultant review. The risk should be re-assessed if clinical condition changes or before subsequent consultant review, and prophylaxis should be adjusted accordingly. The tool then suggests the use of different VTE prophylaxis measures guided by patient risk and contraindications.

There are pharmacological and mechanical approaches to managing the risk of VTEs. In patients with significantly lowered mobility: bed-bound, unable to walk unaided, or following a sedentary lifestyle, mechanical prophylaxis such as 
thromboembolism deterrent (TED) stockings or intermittent pneumatic compression devices may be indicated. These compression devices increase venous blood-flow and decrease venous stasis to prevent thrombus formation [4]. Some patients require pharmacological interventions, where low molecular weight heparin (LMWH) is the primary drug of choice to mitigate the thrombus risk. Pharmacological interventions, if determined to be necessary, should be initiated within 14 hours of admission. The significant burden of VTEs can be easily prevented using the simple thromboprophylaxis of mechanical and cost-effective pharmacological interventions. To provide extra incentive for National Health Service (NHS) Trusts to follow guidance, the National Quality requirement in NHS Standard Contract 2019/2020 state that at least 95\% of inpatients need to undergo VTE risk assessment each quarter, if trusts fail to meet this target, they may be subject to a fine [5].

Traditionally, NHS hospital trusts use(d) paper-based patient records for in-hospital documentation, including VTE assessments. This process was deemed obsolete as it is susceptible to human error, is not very secure, storage is difficult to scale and importantly not optimal for productivity within healthcare teams [6]. Therefore, on the 7th of January 2019, NHS England published the 'NHS Long Term Plan' that sets out the national priorities for healthcare over the next 10-years, including the fate of record keeping in the NHS [7]. In this plan, all trusts, including St. George's hospital NHS trust, are required to switch from paperbased records to digital records by 2023. As such, St. George's NHS trust started the gradual shift to Electronic Patient Records (EPR) in 2018, limiting the use of paper-based records to select departments. This meant that the process for VTE assessment, prescriptions and documentation evolved to fit the new record keeping system.

Prior to the implementation of EPR, a designated area in paper drug charts (Fig. 1) was used for VTE assessment and prescription. Patients were risk assessed by the admitting doctor and appropriate VTE prophylaxis was then prescribed. It is common practice for the pharmacist to review the drug chart to ensure that the assessment was complete and that no errors were made. This process required doctors and pharmacists to remember to complete the assessment and provide prescriptions. However, following the implementation of EPR, VTE assessments are completed electronically as soon as the patient is admitted. The computer system prompts doctors to complete the appropriate forms and enter the correct prescriptions and administer them. Similarly, 24-hour reassessments of VTE risk are completed electronically with pop-up reminders for staff to complete them. These built-in electronic measures are expected to increase adherence rates to VTE assessment and prescription.

Due to the rapid rise of EPR usage in the UK, it is predicted that the adherence of NHS trusts to NICE guidance for VTE assessment will be affected. Since correct VTE assessment and prescription is vital to patient safety and avoiding fines, this research aims to determine the effect of EPR on adherence to national VTE assessment guidelines in the early stages of switching to the electronic system at St. George's Hospital NHS Trust. It is hypothesized that the assessment, prescription and implementation of LMWH and TED stockings would increase with the implementation of EPR, allowing the trust to meet a higher number of assessments than historically achieved, allowing the Trust to exceed national targets.

\section{Methods}

\section{Ethical Approval}

After consulting the appropriate local departments at St. George's Hospital NHS Trust, it was determined that such studies do not require ethical approval as they fall under the premise of 'internal audits'. Nonetheless, the study was conducted in accordance to the standards of ethics outlined in the Declaration of Helsinki.

\section{Study Design and Participants}

A cross-sectional study observing all the patients under the General Surgery team at Nye Bevan Unit, St. George's Hospital from $26^{\text {th }}$ February to $18^{\text {th }}$ March $2018(n=154)$ and $31^{\text {st }}$ October to $25^{\text {th }}$ November $(n=151) 2018$ was completed by manually searching patients' notes to establish baseline information of adherence to national VTE prophylaxis guidelines.

As discussed above the study explores the impact of the EPR system on the observance of the NICE thromboprophylaxis guidelines in the hospital, prior to and immediately after its implementation. During the first data collection period (February to March), patient's hardcopy medical records were reviewed. This was analysed (seen below, Results) and compared to the National Quality Requirement in the NHS Standard Contract 2017/2019 of 95\% patients undergoing VTE risk assessment. Seven months 
later (October to November) the EPR system was introduced, immediately after which a further observation of VTE prophylaxis adherence was conducted.

Thromboprophylaxis types that were assessed were subcutaneous LMWH - Dalteparin 5000 units daily is commonly used at St. George's Hospital, and TED stockings. The recommended prophylaxis methods, their administration and monitoring procedures were based off the Department of Health's Risk Assessment for VTEs, NICE guidelines [3], and St. George's Hospital NHS Trust procedures.

The inclusion criteria of this study included all patients admitted under the general surgery team, either as an emergency or elective admission. Any patient who had contraindications to prophylaxis (Table 1, Figure 1) were included, as the study explores the adherence to VTE guidelines and accuracy of VTE prophylaxis form completion. Exclusion criteria encompassed patients who were under 18 years of age. Surgical procedures conducted by the general surgery team include (but are not limited to), hernia repairs, gastrointestinal, urological procedures, and other laparotomies or laparoscopies.

\section{Data Collection}

Surgical take lists were reviewed by data collectors (AA, FE, BM, AM, MS), under the supervision of a local registrar every morning over the 3-week period. Patients notes were accessed and analysed for (Table 1):

- Whether a VTE prophylaxis risk assessment had been conducted - either on drug charts or informally in their notes on admission and on re-assessment 24-hrs later (Figure 1);

- Whether the risk assessment was accurately completed, filling out all aspects of the assessment sheet, recording the date, time, and clinician's signature;

- If prophylaxis was prescribed correctly or contraindications were recorded by ensuring healthcare professionals prescribed using risk stratification for thrombosis and bleeding risk, and co-morbidities (such as obesity, and renal impairment) according to NICE guidance. These factors determine whether a patient is high or low risk of VTE (Figure 1);

- If patients were compliant - assessed by data collectors personally checking if medication had been taken, TED stockings been given and if they were worn by consulting with patients themselves.

Patient's notes included initial Accident and Emergency (A\&E) admission assessments, referral letters, clerkings, physical examinations, and drug charts. A proforma was created for data collection with explicit criteria for data extraction.

Pharmacological and mechanical prophylaxis were identified from documented evidence of patient's prescription with a signature from the relevant healthcare professional (HCP).

\section{Statistical analysis}

All data was collected on a Microsoft Office database under a protected server, and statistical analysis of results was carried out using SPSS. Data collected from patients' notes can be seen in Table 1. Descriptive statistics were used to compare demographic and clinical variables. Two sets of data were compared, pre- and post-implementation of EPR, to observe its impact on adherence. A two proportion Z-test was used to compare the data of the two populations. These results were compared with a p-value, with a level of significance set at $p<0.05$. The formulas used to compare two data sets are as follows:

Percentage difference $=$

$\frac{\text { pre-implementation data set - post-implementation data set }}{\text { post-implementation data set }} \times 100 \%$

post-implementation data set

$z=\frac{\left(\beta_{1}-\beta_{2}\right)-0}{\sqrt{\beta(1-\beta)\left(\frac{1}{n_{1}}+\frac{1}{n_{2}}\right)}}$

$\beta 1$; - is the proportion in the first data set, $\beta 2$ - is the proportion in the second data set; - is the proportion of the combine data set.

Table 1 Data collected from patients' notes

Page $4 / 13$ 


\begin{tabular}{|c|c|}
\hline \multirow[t]{6}{*}{ Background } & Date of birth/Age \\
\hline & Sex \\
\hline & Admission Date \\
\hline & Discharge Date \\
\hline & Weight \\
\hline & Height \\
\hline \multirow[t]{5}{*}{ Evidence of Prophylaxis } & Contraindications to Thromboprophylaxis Prescription \\
\hline & Completion of Risk Assessment \\
\hline & LMWH Prescription \\
\hline & TEDs Prescription \\
\hline & Compliance \\
\hline
\end{tabular}

\section{Results}

Table 2 Demographics of study participants

\begin{tabular}{|lll|}
\hline & Pre-implementation of EPR $(\mathrm{n}=154)$ & Post-implementation of EPR $(\mathrm{n}=151)$ \\
\hline Age $($ mean \pm SD $)$ & $52 \pm 20.48$ & $52 \pm 20.59$ \\
Sex & & $83(55 \%)$ \\
Female $(\mathrm{n}(\%))$ & $102(66 \%)$ & $68(45 \%)$ \\
Male $(\mathrm{n}(\%))$ & $52(34 \%)$ & \\
Risk of VTE & & $62(41 \%)$ \\
High (n (\%)) & $75(49 \%)$ & $89(59 \%)$ \\
Low (n (\%)) & $79(51 \%)$ & $26.9^{\ddagger} \pm 3.70$ \\
\hline BMI (mean \pm SD) & $25.7^{\dagger} \pm 4.80$ & \\
\hline
\end{tabular}

EPR: Electronic Patient Record; BMI: Body Mass Index (weight/height ${ }^{2}$ ); VTE: Venous Thromboembolism; n: number; SD: Standard Deviation

${ }^{*}$ Patients were categorised as high risk if there was at least one risk factor for VTE present as outlined in NICE guidelines [NG89] (Figure 1)

+19 patients did not have a recorded BMI

‡17 patients did not have a recorded BMI

The study sample pre- and post-implementation of EPR were similar for age and sex. Importantly, factors affecting the prescription of VTE prophylaxis i.e. risk of VTE and BMI were also comparable.

Table 3 Initial VTE assessment and 24-hour reassessment in pre- and post-EPR implementation populations 


\begin{tabular}{|c|c|c|c|c|}
\hline & $\begin{array}{l}\text { Pre-implementation of EPR } \\
(\mathrm{n}(\%))\end{array}$ & $\begin{array}{l}\text { Post-implementation of EPR } \\
(\mathrm{n}(\%))\end{array}$ & \multirow[t]{2}{*}{$\begin{array}{l}\% \\
\text { change }\end{array}$} & \multirow[t]{2}{*}{$\begin{array}{l}\mathrm{P} \text { - } \\
\text { value }\end{array}$} \\
\hline & $n=154$ & $n=151$ & & \\
\hline \multicolumn{5}{|l|}{ VTE assessment completed } \\
\hline Correctly & & $137(94 \%)$ & & \\
\hline Incorrectly & $141(95 \%)$ & $9(6 \%)$ & $-2.84 \%$ & 0.40 \\
\hline \multirow[t]{2}{*}{ Total } & $7(5 \%)$ & $146(97 \%)$ & $-28.57 \%$ & 0.29 \\
\hline & $148(96 \%)$ & & $-1.35 \%$ & 0.39 \\
\hline VTE assessment not completed & $6(4 \%)$ & $5(3 \%)$ & $-16.67 \%$ & 0.39 \\
\hline 24-hour reassessment & & $75(95 \%)$ & & \\
\hline Correctly & & $4(5 \%)$ & & \\
\hline Incorrectly & $88(96 \%)$ & $79\left(54 \%{ }^{*}\right)$ & $-14.77 \%$ & 0.08 \\
\hline \multirow[t]{2}{*}{ Total } & $4(4 \%)$ & & $0.00 \%$ & 0.49 \\
\hline & $92\left(62 \%{ }^{*}\right)$ & & $-14.13 \%$ & 0.08 \\
\hline \multicolumn{5}{|l|}{$\begin{array}{l}\text { 24-hour reassessment not } \\
\text { completed }\end{array}$} \\
\hline \multicolumn{5}{|l|}{ No reason } \\
\hline \multicolumn{5}{|l|}{ Discharged } \\
\hline \multirow[t]{2}{*}{ Total } & $24(43 \%)$ & $20(30 \%)$ & $-16.67 \%$ & 0.27 \\
\hline & $56\left(38 \%^{*}\right)$ & $67\left(46 \%{ }^{*}\right)$ & $19.64 \%$ & 0.08 \\
\hline
\end{tabular}

EPR: Electronic Patient Record; VTE: Venous Thromboembolism; n: number

P-value $<0.05$ was considered significant

${ }^{*}$ Percentage calculated using number of 'VTE assessment completed total' as population

The total VTE assessments completed pre- and post-EPR implementation increased from $96 \%$ to $97 \%$ respectively, $p=0.39$, the majority of which were completed correctly with $95 \%$ pre-EPR implementation and $94 \%$ post-EPR implementation, $p=0.40 .4 \%$ of the patients did not have a VTE assessment completed pre-EPR implementation and 3\% post-EPR implementation, $p=0.39$.

$62 \%$ of the total patients had a 24 -hour reassessment completed pre-EPR implementation when compared to $54 \%$ post-EPR implementation, $p=0.08$. Similar to the initial assessment, most 24 -hour reassessments were completed correctly with $96 \%$ preEPR implementation and $95 \%$ post-EPR implementation, $p=0.08$. 38\% of the patients did not have a 24-hour reassessment completed pre-EPR implementation and $46 \%$ post-EPR implementation, $p=0.08 \%$. Patients who had no reason for not having a $24-$ hour reassessment completed increased significantly from $57 \%$ to $70 \%$ pre- and post-EPR implementation respectively, $p=0.02$.

Table 4 Prescription and administration of LMWH in pre- and post-EPR implementation populations 


\begin{tabular}{|lllll|}
\hline & Pre-implementation of EPR $(\mathrm{n}=154)$ & Post-implementation of EPR $(\mathrm{n}=151)$ & $\%$ change & P-value \\
\hline Prescribed & $126(82 \%)$ & $116(77 \%)$ & $-7.94 \%$ & 0.14 \\
\hline Not prescribed & & & & \\
No reason & $8(29 \%)$ & $15(43 \%)$ & $87.50 \%$ & 0.06 \\
Not assessed & $6(21 \%)$ & $4(11 \%)$ & $-33.33 \%$ & 0.27 \\
Contraindicated & $14(50 \%)$ & $16(46 \%)$ & $14.29 \%$ & 0.33 \\
Total & $28(18 \%)$ & $35(23 \%)$ & $25.00 \%$ & 0.14 \\
\hline Administered & & & $11.88 \%$ & $<0.01$ \\
Prescribed & $101(100 \%)$ & $113(100 \%)$ & $0.00 \%$ & - \\
Not prescribed & $0(0 \%)$ & $0(0 \%)$ & $11.88 \%$ & $<0.01$ \\
Total & $101\left(80 \%{ }^{*}\right)$ & $113\left(97 \%{ }^{*}\right)$ & & \\
Not Administered & & & $-66.67 \%$ & 0.05 \\
No reason & $9(36 \%)$ & $3(100 \%)$ & $-100.00 \%$ & $<0.01$ \\
Contraindicated & $9(36 \%)$ & $0(0 \%)$ & $-100.00 \%$ & $<0.01$ \\
Not compliant & $7(28 \%)$ & $0(0 \%)$ & $-88.00 \%$ & $<0.01$ \\
Total & $25\left(20 \%^{*}\right)$ & $3\left(3 \%{ }^{*}\right)$ & & \\
\hline
\end{tabular}

EPR: Electronic Patient Record; n: number

P-value $<0.05$ was considered significant

${ }^{*}$ Percentage calculated using number of 'prescribed' as population

The total LMWH prescriptions decreased from $82 \%$ to $77 \%$ pre- and post-EPR implementation respectively, $p=0.14$. Of the patients not prescribed LMWH (18\% pre-EPR and $23 \%$ post-EPR implementation, $p=0.14$ ), $50 \%$ compared to $46 \%$ were due to contraindications pre- and post-EPR implementation respectively, $p=0.33$. The remainder of patients with missing prescriptions were due to a lack of an assessment $(p=0.27)$ or no documented reason $(p=0.06)$.

Of those prescribed $\mathrm{LMWH}, 80 \%$ were given the prescription pre-EPR implementation compared to $97 \%$ post-EPR implementation, a significant increase with $p<0.01$. $100 \%$ of patients given LMWH were prescribed it pre- and post-EPR implementation, $p<0.01$. Of those not given the LMWH prescription (20\% pre-EPR and $3 \%$ post-EPR implementation, $p<0.01$ ), $36 \%$ were due to contraindications pre-EPR compared to $0 \%$ post-EPR implementation, $p<0.01$. The remainder of those who were not administered were due to lack of compliance $(p<0.01)$ or for no documented reason $(p=0.05)$.

Table 5 Prescription and administration of TED stockings in pre- and post-EPR implementation populations 


\begin{tabular}{|c|c|c|c|c|}
\hline & Pre-implementation of EPR $(n=154)$ & Post-implementation of EPR $(n=151)$ & $\%$ change & P-value \\
\hline Prescribed & $130(84 \%)$ & $96(64 \%)$ & $-26.15 \%$ & $<0.01$ \\
\hline \multicolumn{5}{|l|}{ Not prescribed } \\
\hline No reason & $15(63 \%)$ & $38(69 \%)$ & $153.33 \%$ & $<0.01$ \\
\hline Not assessed & $6(25 \%)$ & $9(16 \%)$ & $50.00 \%$ & 0.20 \\
\hline Contraindicated & $3(13 \%)$ & $8(15 \%)$ & $166.67 \%$ & 0.06 \\
\hline Total & $24(16 \%)$ & $55(36 \%)$ & $129.17 \%$ & $<0.01$ \\
\hline \multicolumn{5}{|l|}{ Administered } \\
\hline Prescribed & $92(96 \%)$ & $81(93 \%)$ & $-11.96 \%$ & 0.03 \\
\hline Not prescribed & $4(4 \%)$ & $6(7 \%)$ & $50.00 \%$ & 0.14 \\
\hline Total & $96\left(72 \%^{*}\right)$ & $87\left(85 \%^{\star}\right)$ & $-9.38 \%$ & 0.01 \\
\hline \multicolumn{5}{|l|}{ Not Administered } \\
\hline No reason & $23(61 \%)$ & $10(67 \%)$ & $-56.52 \%$ & 0.05 \\
\hline Contraindicated & $1(3 \%)$ & $0(0 \%)$ & $-100.00 \%$ & 0.19 \\
\hline Not compliant & $14(37 \%)$ & $5(33 \%)$ & $-64.29 \%$ & 0.06 \\
\hline Total & $38\left(28 \%{ }^{*}\right)$ & $15\left(15 \%^{\star}\right)$ & $-60.53 \%$ & 0.01 \\
\hline
\end{tabular}

EPR: Electronic Patient Record; n: number

P-value $<0.05$ was considered significant

${ }^{*}$ Percentage calculated using number of 'prescribed' as population

The total TED stocking prescriptions decreased significantly from $84 \%$ to $64 \%$ pre- and post-EPR implementation respectively, $p<0.01$. Of the patients not prescribed TED stockings ( $16 \%$ pre-EPR and $36 \%$ post-EPR implementation, $p<0.01$ ), $13 \%$ compared to $15 \%$ were due to contraindications pre- and post-EPR implementation respectively, $p=0.06$. The remainder of patients with missing prescriptions were due to a lack of an assessment $(p=0.20)$ or no documented reason $(p<0.01)$.

Of those prescribed TED stockings, $72 \%$ were given the prescription pre-EPR implementation compared to $85 \%$ post-EPR implementation, a significant increase with $\mathrm{p}=0.01$. Of the patients given TED stockings, $96 \%$ had a prescription for them pre-EPR implementation compared to $93 \%$ post-EPR implementation, $p=0.03$. Of those not given TED stockings ( $28 \%$ pre-EPR and $15 \%$ post-EPR implementation, $\mathrm{p}=0.01$ ), $3 \%$ were due to contraindications pre-EPR implementation compared to $0 \%$ post-EPR implementation, $p=0.19$. The remainder of those who were not administered was due to a lack of compliance $(p=0.06)$ or for no documented reason $(p=0.05)$.

\section{Discussion}

As most VTE's are easily preventable, it is imperative to investigate the measures in place to avoid such events and reduce unnecessary morbidity and mortality. This study aimed to explore the effects of converting to EPR from paper records on the adherence to NICE thromboprophylaxis guidelines in a tertiary centre hospital. EPR has been pushed to be fully implemented within the NHS to move towards more paperless technology [7] and therefore it is vital to investigate the impact of completion of key assessments and tasks within NHS trusts.

\section{VTE Risk Assessments}


There was no statistically significant change in the completion rate of VTE risk assessments on admission or after 24 hours following the conversion to EPR. Using paper records, the Trust met the national target set out in the NHS Standard Contract $2019 / 2020$ at a $96 \%$ completion rate of VTE assessments, which increased to $97 \%$ post-implementation of EPR $(p=0.39)$. This rise in assessment rate, even though not statistically significant, may be due to the benefits of the EPR system, such as including reminders for staff to complete the risk assessment proforma. This VTE risk assessment completion rate compares similarly to results in a study conducted at St. George's Hospital NHS Trust in 2014 [8], which reported a completion rate of up to $98 \%$ using paper records. This demonstrates the general surgical department has been consistently meeting VTE risk assessment targets over several years. Encouragingly, the number of VTE risk assessment forms that were not completed for surgical patients decreased from $4 \%$ with paper records to $3 \%$ with electronic records. Although this difference was not statistically significant $(p=0.39)$, it shows that EPR systems can perhaps increase effectiveness of completing forms on time. The study also assessed whether the risk assessment forms were completed correctly or not. The data shows no statistically significant difference between paper ( $5 \%$ completed incorrectly) and electronic records ( $6 \%$ completed incorrectly) $(p=0.29)$ in terms of proportion of VTE risk assessments that were completed correctly or incorrectly. This counters the argument that EPR systems can significantly reduce human error and improve effectiveness.

As required by the local guidelines St. George's Hospital guidelines, the VTE risk must be re-assessed at 24 hours post-admission. Overall the completion rate was much lower than on admission, at $62 \%$ before the implementation of EPR, with $57 \%$ of reassessments not performed and lacking a reason. The re-assessment completion rate fell to $54 \%$ after the introduction of the EPR system, and $70 \%(p=0.02)$ of the missing re-assessments did not provide a reason for why they were incomplete. This was unexpected because it was hypothesized that prompts and alerts on the EPR system would remind staff to complete the 24-hour re-assessments. However, it was not mandatory on the EPR system to complete the 24-hour re-assessment forms, which meant that alerts and pop-ups could be simply closed or ignored by staff. In addition, as data collection was conducted shortly after the implementation of EPR, it is likely that staff had limited training and were unfamiliar with the system, and therefore not appropriately recording reasons for incomplete VTE assessments. Nevertheless, a similar pattern was found by [8] St. George's Hospital in 2014 , with around $63 \%$ to $77 \%$ of 24 -hour re-assessments being completed correctly. Therefore, the implementation of the EPR system seems to have not significantly improved the completion of VTE risk assessments compared to using paper records, with consistently similar rates since 2014. A recommendation to improve these VTE risk assessment completion rates is to improve the IT systems training for new staff and run a "refresher" training session for existing staff on correctly completing the VTE risk assessments using the EPR system. It is also possible to make it more difficult for doctors to bypass alerts on the computer about completing VTE risk assessments on time, which may help improve rates without hindering emergency access to medical records.

\section{VTE Prophylaxis}

In terms of pharmacological methods, LMWH has proved to be an effective method of VTE prophylaxis across several medical and surgical settings, highlighting its importance in admitted patients. LMWH as a method of prophylaxis is routinely used in acutely ill patients, usually in the absence of bleeding risk factors. However, routine assessment of patients has been described in NICE as well as in some specialities in the UK such as Royal College of Obstetrics and Gynaecology [9]. Overall prescription of LMWH went down from $82 \%$ to $77 \%$ ( $p=0.14)$ post-EPR implementation. Post-implementation of EPR revealed $12.5 \%$ of patients were not prescribed LMWH either with no reason stated or because no assessment was conducted. Similar results of low prescription rates of VTE and LMWH seems to be a common occurrence worldwide and in UK NHS trusts. A prospective study in 2005 analysed thromboprophylaxis prescription in two NHS teaching hospitals and supported the findings of VTE and LMWH under prescription [10]. All patients with LMWH given had a prescription both pre- and post-EPR implementation. These results demonstrated a significant $p$-value $(p<0.01)$. This suggests that encouraging early assessment is key for ensuring prescription and avoids situations where VTE assessments of these patients are forgotten about throughout their remainder stay in hospital. However, if early assessment occurs and is recorded accurately, this allows for the subsequent process to continue allowing relevant healthcare staff to access records and be aware when re-assessments or changes need to be made. Clear and accurate recording of LMWH prescription additionally allows for increased efficiency in that tasks are not unnecessarily replicated and inherently becomes a reminder for assessments thereafter as there is a record. There were a reported group of patients with no LMWH implementation despite prescription; 25 patients and 3 patients pre-EPR and post-EPR respectively. Out of these patients, 
some had contraindications reported, with a $p$ value of $<0.01$. However, the remainder of patients either did not have a reason recorded for lack of implementation or there was a lack of compliance $(p<0.01)$. It is important to note that lack of reason recorded, and compliance was prominent pre-EPR and this subsided post-EPR. A mixed methods study in 2015 explored the benefits and challenges of EPR implementation within the NHS. The study noted a major benefit of EPR enabled speedier flows of information and increased efficiency of completing tasks [11], which is a similar finding in this study.

There is a clear need for the guidelines and importance of LMWH assessments to be highlighted during hospital inductions. This emphasis may aid in viewing LMWH prescription as part of key initial patient assessment. Identifying key workers to take on this responsibility could help in avoiding situations where tasks are continuously passed on rather than being completed. In contrast to this study and several others, a UK based study conducted across 28 hospitals Scotland and England in 2001 reported relatively high prescription and assessment rates. They suggested that there is a trade-off between promoting and emphasising VTE prescription and cost-effectiveness [12]. As such, this could be a common, inherent issue of implementing cost-friendly ways that would significantly improve prescription rates. Clarke et al also described financial restraints and lack of time for electronic trust induction could hinder the staff use of EPR. Additionally, there is a difference across baseline technology capability in individual trusts, which makes it difficult and unrealistic for hospitals to achieve the same end-goal. This indicates the need for each trust to have their technology capabilities assessed as each trust will have different needs and resources and explains why efficiency in utilising EPR may vary across trusts. The issue of user technological capability can be reflected into this study where staff technology knowledge could be playing a major role in lack of assessment completion [11]. These figures warrant further investigation into identifying the reasons for low LMWH prescriptions and missed assessments as there is a clear discrepancy between hospital performance and nationwide regulations.

As for mechanical methods, TED stockings are often used as VTE prophylaxis. Before the implementation of electronic records $84 \%$ of patients were prescribed TED stockings, which dropped to $64 \%$ with the use of EPR $(p<0.01)$. Of the patients that were not prescribed TEDs, there was no reason stated in the electronic patient records in $69 \%(p<0.01)$ of cases. The data shows a worrying pattern of decreasing rates of accurate record keeping in regards to the use of TEDs even with EPR. A possible explanation for TED prescription rates falling with the implementation of EPR may be that this study was conducted in the period immediately after the Trust had converted to electronic records. TED stockings are a non-pharmacological prescription, and therefore may not have been straightforward for staff to prescribe when they were unfamiliar with the EPR system, therefore dropping the TED prescription rate. As outlined by Hertzum M et al [13], Cambridge University Hospital also experienced troubles with consistency of care, including venous thromboembolism assessments, after their electronic patient record system, Epic, was implemented. The Care Quality Commission inspection only found significant improvements in their record keeping two years after the implementation of EPR. Therefore, it is possible that the TED prescription rates fell due to a 'productivity dip' [14] phase after the EPR system was implemented. This is possibly due to staff being unfamiliar with the system or technological glitches in the software, etc.

While TEDs were often prescribed, they were not always administered by staff, and vice versa, anti-embolism stockings were sometimes not prescribed but still given to patients by staff. Administration of TEDs (defined as the patient found correctly wearing the TED stockings) fell from $96 \%$ to $93 \%(p=0.03)$ with the transition from paper records to EPR. Five patients were not compliant with wearing their TEDs (post-implementation of EPR), but more often there was no reason stated in the notes as to why the stockings were not given or worn by the patient ( $67 \%$ of cases). 6 patients were wearing TED stockings given by staff even though a prescription had not been completed on the electronic records system. This may again be due to staff being unfamiliar with the new software or poorly trained in how to record such details correctly, as well as staff being able to bypass prompts to fill out the forms fully. According to Restrepo P et al [15], it was difficult to monitor proper application of TEDs and have consistent accurate documentation in their department because of lack of clear guidelines and strong evidence, which would help standardise and optimise mechanical VTE prophylaxis.

The scope of this study was simply focused on completeness of patient records, comparing paper to electronic notes, in regard to VTE risk assessments and prophylaxis. The transition to EPR is an enormous undertaking for a hospital and impacts the consistency in care for patients in many other ways. This study did not assess the impact on how correctly VTE risk assessments were done (e.g. whether the VTE prophylaxis prescribed was correct or whether the correct size of TED stockings were given to 
patients), and did not record data on patient's previous risks for VTE, such as use of combined oral contraceptive pill, past history of DVTs, active cancer, etc., which would have been needed to make a judgement on the appropriateness of the prescriptions. Also, data was not recorded on the presenting complaint, the diagnosis and which operation they were admitted for, or their length of bed rest pre- or post-op, which all would have further impacted their VTE risk. Staff attitude is also a key parameter in the success of sustainable change, and therefore it would have been useful to include in the study.

The main limitation of the study is that patients were only selected from the general surgery list and only from one tertiary centre. This limits the applicability of the results to other departments and to larger geographic areas. Additionally, in the future a larger sample size should be used, thus making it easier to achieve statistically significant result. It is challenging to maintain consistently high standards of care during large transitions such as implementing EPR, especially with frequently rotating staff (e.g. junior doctors). This study occurred in the period immediately after electronic records came into use in the department and thus staff may not have been comfortable with using the software or may not have had sufficient training, which may have influenced the results.

\section{Conclusions}

This study highlighted the importance of a multidisciplinary approach when trying to drive change in a large establishment with set routines. When all staff are actively engaged in changing a process, it eases the operation significantly. This is particularly important in VTE prophylaxis due to thrombotic events being a large, preventable cause of death for in-patients. While a paperless NHS allows for easier access across different settings, there is an inherent issue of lack of training in using EPR. Varied technological capabilities across trusts make this process complex. Though the current practise in the tertiary centre in this study did meet the national guidelines, there is still much room for improvement particularly in the VTE risk 24-hour re-assessments. A multifactorial approach is required to achieve technological goals including enhancing staff attitude, introducing increased EPR training and assessments in individual trust technological needs to achieve a standard use capability.

\section{List Of Abbreviations}

VTE: Venous Thromboembolism; DVT: Deep Venous Thrombosis; PE: Pulmonary Embolism; NICE: National Institute for Health and Care Excellence; UK: United Kingdom; TED: Thromboembolism Deterrent; LMWH: Low Molecular Weight Heparin; NHS: National Health Service; EPR: Electronic Patient Records; A\&E: Accident and Emergency; HCP: Healthcare Professional; BMI: Body Mass Index; n: number; SD: Standard Deviation.

\section{Declarations}

\section{Ethics approval and consent to participate}

After consulting the appropriate local departments at St. George's Hospital NHS Trust, it was determined that such studies do not require ethical approval as they fall under the premise of 'internal audits'. Nonetheless, the study was conducted in accordance to the standards of ethics outlined in the Declaration of Helsinki.

\section{Consent for publication}

Not applicable.

\section{Availability of data and materials}

The datasets used and/or analysed during the current study are available from the corresponding author on reasonable request.

\section{Competing interests}

The authors declare that they have no competing interests.

\section{Funding}

Page $11 / 13$ 
Not applicable.

\section{Authors' contributions}

The manuscript has been read and approved by all named authors, and there are no other persons who could satisfy the criteria for authorship but are not listed. AA, MS, AM, BM, FME contributed equally to the study concept and design, data collection, interpretation of data, drafting the manuscript and manuscript revisions. All authors read and approved the final manuscript.

\section{Acknowledgements}

We would like to thank Mr. Rajarajan Ramamoorthy for his supervision on our research, as well as the St. George's Hospital Nye Bevan (Surgical Admissions Unit) for their assistance and access to the ward.

\section{Authors' information}

Not applicable.

\section{References}

1. Heit JA. Venous thromboembolism: disease burden, outcomes and risk factors. J Thromb Haemost. 2005;3(8):1611-1617.

2. NICE Guidance. Venous thromboembolism in over 16s: reducing the risk of hospital-acquired deep vein thrombosis or pulmonary embolism, NICE guideline [NG89]. https://www.nice.org.uk/guidance/ng89/chapter/Context. Accessed 3 August 2020.

3. NICE Guidance. Venous thromboembolism in over 16s: reducing the risk of hospital-acquired deep vein thrombosis or pulmonary embolism, NICE guideline [NG89]. https://www.nice.org.uk/guidance/ng89. Accessed 3 August 2020.

4. Moheimani F, Jackson DE. Venous thromboembolism: classification, risk factors, diagnosis, and management. ISRN Hematol. 2011;2011:124610.

5. NHS Standard Contract 2019/20 Particulars. https://www.england.nhs.uk/publication/nhs-standard-contract-2019-20particulars-full-length/. Accessed 2 August 2020.

6. Mathioudakis A, Rousalova I, Gagnat AA, Saad N, Hardavella G. How to keep good clinical records. Breathe (Sheff). 2016;12(4):369-373.

7. NHS Long Term Plan. https://www.longtermplan.nhs.uk/. Accessed 2 August 2020.

8. Johnson O, Kumar S. Risk assessment and prophylaxis of venous thromboembolism in surgical inpatients: improving adherence to national guidelines. BMJ Qual Improv Rep. 2015;4(1):u206691.w2692.

9. Cardiff and Vale University Health Board. Thromboprophylaxis Policy for Adult Patients Admitted as Inpatients. 2015. http://www.cardiffandvaleuhb.wales.nhs.uk/sitesplus/documents/1143/Agenda\%20item\%207.4b\%20Thromboprophylaxis\% 20Policy\%20GJS\%20\%284\%29.pdf. Accessed 2 August 2020.

10. Rashid ST, Thursz MR, Razvi NA, Voller R, Orchard T, Rashid ST, Shlebak AA. Venous thromboprophylaxis in UK medical inpatients. J R Soc Med. 2005;98(11):507-512.

11. Clarke A, Adamson J, Sheard L, Cairns P, Watt I, Wright J. Implementing electronic patient record systems (EPRs) into England's acute, mental health and community care trusts: a mixed methods study. BMC Med Inform Decis Mak. 2015;15:85.

12. Campbell SE, Walke AE, Grimshaw JM, Campbell MK, Lowe GD, Harper D, Fowkes FG, Petrie JC, Tempest Group. The prevalence of prophylaxis for deep vein thrombosis in acute hospital trusts. Int J Qual Health Care. 2001;13(4):309-316

13. Hertzum M, Ellingsen $G$. The implementation of an electronic health record: Comparing preparations for Epic in Norway with experiences from the UK and Denmark. Int. J. Med. Inform. 2019;129:312-317.

14. Priestman W, Sridharan S, Vigne H, Collins R, Seamer L, Sebire NJ. What to expect from electronic patient record system implementation: Lessons learned from published evidence. J Innov Health Inform. 2018;25(2):92-104.

15. Restrepo P, Jameson DL, Carroll DL. Improving deep vein thrombosis prophylaxis with mechanical modalities in surgical intensive care unit. J Nurs Care Qual. 2015;30(1):31-37.

Page $12 / 13$ 


\section{Figures}

\begin{tabular}{|c|c|c|c|}
\hline \multicolumn{4}{|c|}{ Risk assessment for venous thromboembolism (VTE) - ALL ADULT ADMISSIONS (paeds case by case) } \\
\hline 0 & Surgical patient & \multirow{2}{*}{0} & \multirow{2}{*}{$\begin{array}{l}\text { Medical patient NOT expected to have significantly reduced } \\
\text { mobility relative to normal state }\end{array}$} \\
\hline 0 & $\begin{array}{l}\text { Medical patient expected to have ongoing reduced mobility } \\
\text { relative to normal state }\end{array}$ & & \\
\hline \multicolumn{2}{|r|}{ Assess for thrombosis and bleeding risk using the tables below } & \multicolumn{2}{|r|}{ SIGN BELOW and Risk assessment complete } \\
\hline
\end{tabular}

\begin{tabular}{|l|l|l|l|}
\hline \multicolumn{2}{|l|}{1 Thrombosis risk - ANY tick indicates high risk of VTE } & $\bigcirc$ & No risk factors for thrombosis (=low risk of VTE) \\
\hline \multicolumn{2}{|l|}{ Patient related } & Admission related \\
\hline$\bigcirc$ & Age >60yrs & $\bigcirc$ & $\begin{array}{l}\text { Acute surgical admission with inflammatory or intra-abdominal } \\
\text { condition }\end{array}$ \\
\hline$\bigcirc$ & Dehydration & $\bigcirc$ & Critical care admission \\
\hline$\bigcirc$ & Known thrombophilia & $\bigcirc$ & Significantly reduced mobility for 3 days or more \\
\hline$\bigcirc$ & Obesity (BMIT >30kg/m2) $\uparrow$ & $\bigcirc$ & Surgery with significant reduction in mobility \\
\hline$\bigcirc$ & Varicose veins with phlebitis & $\bigcirc$ & Hip fracture \\
\hline$\bigcirc$ & Personal history/first degree relative with history of VTE & $\bigcirc$ & Hip or knee replacement \\
\hline$\bigcirc$ & Use of hormone replacement therapy & $\bigcirc$ & Lower limb paralysis excluding stroke \\
\hline$\bigcirc$ & Use of oestrogen-containing oral contraceptive therapy & $\bigcirc$ & Immobilising plaster case \\
\hline$\bigcirc$ & Active cancer or cancer treatment & $\bigcirc$ & Total anaesthetic + surgery time >90 minutes \\
\hline$\bigcirc$ & $\begin{array}{l}\text { One or more significant medical co-morbidities (e.g. } \\
\text { cardiac, respiratory, metabolic, endocrine, infectious or } \\
\text { inflammatory conditions) }\end{array}$ & $\bigcirc$ & $\begin{array}{l}\text { Pelvic or lower limb surgery with total anaesthetic + surgery time } \\
>60 \text { mins }\end{array}$ \\
\hline$\bigcirc$ & $\begin{array}{l}\text { Pregnancy or <6 weeks post-partum (see separate obstetric } \\
\text { VTE risk assessment) }\end{array}$ & \\
\hline
\end{tabular}

\begin{tabular}{|c|c|c|c|}
\hline \multicolumn{2}{|r|}{$\begin{array}{l}2 \text { Bleeding risk - ANY tick should prompt clinical staff to consider if } \\
\text { the bleeding risk is sufficient to preclude pharmacological } \\
\text { intervention }\end{array}$} & O & No risk factors for bleeding \\
\hline \multicolumn{2}{|r|}{ Patient related } & \multicolumn{2}{|c|}{ Admission related } \\
\hline O & Active bleeding & $\mathrm{O}$ & ACS protocol \\
\hline Q & Acquired bleeding disorder (such as acute liver failure) & \multirow{2}{*}{ O } & \multirow{2}{*}{$\begin{array}{l}\text { Neurosurgery*, spinal surgery*, eye surgery } \\
\text { *see specific neurosurgical guidance }\end{array}$} \\
\hline 0 & Platelets $<75 \times 10^{9} / \mathrm{L}$ (check on admission) & & \\
\hline $\mathrm{O}$ & $\begin{array}{l}\text { Concurrent use of anticoagulant (such as warfarin with INR }>2 \text { ) } \\
\text { NOACs drugs }\end{array}$ & $\mathrm{O}$ & $\begin{array}{l}\text { Lumbar puncture/epidural/spinal anaesthesia expected in the } \\
\text { next } 12 \mathrm{hrs}\end{array}$ \\
\hline O & $\begin{array}{l}\text { Untreated inherited bleeding disorder (e.g. haemophilia, von } \\
\text { Willebrand disease) }\end{array}$ & $\mathrm{O}$ & $\begin{array}{l}\text { Lumbar puncture/epidural/spinal anaesthesia within previous } \\
4 \text { hrs }\end{array}$ \\
\hline $\mathrm{O}$ & Acute stroke (used with caution - discuss with Stroke Team) & 0 & Other procedures with high bleeding risk \\
\hline 0 & Severe hypertension $(>180 / 110 \mathrm{mmHg})$ & & \\
\hline
\end{tabular}

\begin{tabular}{|c|c|c|c|c|c|c|}
\hline \multirow[b]{2}{*}{ VTE risk category } & \multicolumn{4}{|c|}{ Risk assessments (tick box as appropriate) } & \multicolumn{2}{|c|}{ Recommended prophylaxis for adults } \\
\hline & $\begin{array}{c}\text { Pre- } \\
\text { admission } \\
\end{array}$ & $\begin{array}{c}\text { On } \\
\text { admission } \\
\end{array}$ & $\begin{array}{l}\text { 24hrs post- } \\
\text { admission }\end{array}$ & $\begin{array}{l}\text { Change in } \\
\text { condition }\end{array}$ & Surgical patients & Medical patients \\
\hline $\begin{array}{r}\text { High } \\
\text { (with low risk of } \\
\text { bleeding) }\end{array}$ & & & & & $\begin{array}{l}\text { Dalteparin } 5000 \text { units daily }{ }^{+} \\
+ \text {anti-embolism stockings }{ }^{\ddagger} \\
+/- \text { sequential compression } \\
\text { devices } \\
+ \text { early mobilisation }\end{array}$ & $\begin{array}{l}\text { Dalteparin } 5000 \text { units dailyt } \\
+ \text { early mobilisation }\end{array}$ \\
\hline $\begin{array}{r}\text { High } \\
\text { (with significant risk } \\
\text { of bleeding) }\end{array}$ & & & & & $\begin{array}{l}\text { Anti-embolism stockingst } \\
+ \text { +- sequential compression } \\
\text { devices } \\
+ \text { early mobilisation }\end{array}$ & $\begin{array}{l}\text { Anti-embolism stockings } \neq \\
+ \text { +- sequential compression } \\
\text { devices } \\
+ \text { early mobilisation }\end{array}$ \\
\hline Low & & & & & Early mobilisation & Early mobilisation \\
\hline Date assessment & & & & & \multirow{5}{*}{\multicolumn{2}{|c|}{$\begin{array}{l}\text { Extra Notes } \\
+ \text { Obesity: use Dalteparin } 5000 \text { units BD (weight }>100 \mathrm{~kg} \text { ) } \\
\text { or } 7500 \text { units BD (weight >150kg) } \\
\text { Renal impairment (CrCl <30m//min or GFR } \\
<30 \mathrm{~mL} / \mathrm{min} / 1.73 \mathrm{~m} \text { ) : use unfractionated heparin } 5000 \text { units BD } \\
\text { \& Do not use antiembolism stockings in the presence of any } \\
\text { contraindications: e.g. stroke, severe peripheral vascular } \\
\text { disease, recent skin graft, peripheral neuropathy, massive leg } \\
\text { oedema/deformity, severe dermatitis, fabric allergy } \\
\text { NOACs = noval oral anticoagulant }\end{array}$}} \\
\hline Time of assessment & & & & & & \\
\hline Clinician name & & & & & & \\
\hline Clinician signature & & & & & & \\
\hline & \multicolumn{4}{|c|}{$\begin{array}{c}\text { Cross through superseded assessments when new } \\
\text { assessment made }\end{array}$} & & \\
\hline
\end{tabular}

\section{Figure 1}

Risk assessment for VTE chart This chart resembles the chart used at St George's University Hospital, created for the purpose of this article. 